\title{
Anti-feline immunodeficiency virus reverse transcriptase properties of some medicinal and edible mushrooms
}

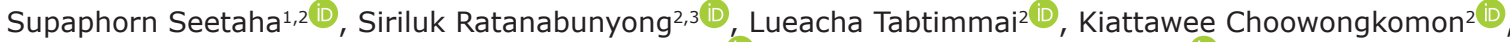 \\ Jatuporn Rattanasrisomporn ${ }^{1,4}$ (iD) and Khuanjarat Choengpanya ${ }^{5}$ (i)
}

1. Center for Advanced Studies for Agriculture and Food, Institute for Advanced Studies, Kasetsart University, Bangkok 10900, Thailand; 2. Department of Biochemistry, Faculty of Science, Kasetsart University, Bangkok 10900, Thailand; 3. Interdisciplinary Graduate Program in Bioscience, Faculty of Science, Kasetsart University, Bangkok 10900, Thailand; 4. Department of Companion Animal Clinical Sciences, Faculty of Veterinary Medicine, Kasetsart University,

Bangkok 10900, Thailand; 5. Program in Applied Biology, Maejo University Phrae Campus, Phrae 54140, Thailand. Corresponding author: Jatuporn Rattanasrisomporn, e-mail: fvetjpn@ku.ac.th

Co-authors: SS: supaporn.se@ku.ac.th, SR: ae.med@hotmail.com, LT: ahcaeul@gmail.com, KC: fsciktc@ku.ac.th, KhCh: khuanjarat_phrae@office365.mju.ac.th

Received: 19-03-2020, Accepted: 06-07-2020, Published online: 05-09-2020

doi: www.doi.org/10.14202/vetworld.2020.1798-1806 How to cite this article: Seetaha S, Ratanabunyong S, Tabtimmai L, Choowongkomon K, Rattanasrisomporn J, Choengpanya K (2020) Anti-feline immunodeficiency virus reverse transcriptase properties of some medicinal and edible mushrooms, Veterinary World, 13(9): 1798-1806.

\begin{abstract}
Background and Aim: Feline immunodeficiency virus (FIV) causes AIDS-like symptoms in domestic and wild cats. Treatment of infected cats has been performed using human anti-HIV drugs, which showed some limitations. This study aimed to determine the anti-FIV potential of some mushrooms.

Materials and Methods: A total of 17 medicinal and edible mushrooms were screened to find their inhibitory effect against FIV reverse transcriptase (FIV-RT). Three solvents, water, ethanol, and hexane, were used to prepare crude mushroom extracts. Fluorescence spectroscopy was used to perform relative inhibition and $50 \%$ inhibitory concentrations $\left(\mathrm{IC}_{50}\right) \mathrm{studies}_{\text {. }}$

Results: The ethanol extract from dried fruiting bodies of Inonotus obliquus showed the strongest inhibition with an $\mathrm{IC}_{50}$ value of $0.80 \pm 0.16 \mu \mathrm{g} / \mathrm{mL}$. The hexane extract from dried mycelium of $I$. obliquus and ethanol and water extracts from fresh fruit bodies of Phellinus igniarius also exhibited strong activities with the $\mathrm{IC}_{50}$ values of $1.22 \pm 0.20,4.33 \pm 0.39$, and $6.24 \pm 1.42 \mu \mathrm{g} / \mathrm{mL}$, respectively. The ethanol extract from fresh fruiting bodies of Cordyceps sinensis, hexane extracts from dried mycelium of I. obliquus, ethanol extracts of Ganoderma lucidum, hexane extracts of fresh fruiting bodies of Morchella esculenta, and fresh fruiting bodies of $C$. sinensis showed moderate anti-FIV-RT activities with $\mathrm{IC}_{50}$ values of $29.73 \pm 12.39$, $49.97 \pm 11.86,65.37 \pm 14.14,77.59 \pm 8.31$, and $81.41 \pm 17.10 \mu \mathrm{g} / \mathrm{mL}$, respectively. These mushroom extracts show anti-FIV potential.
\end{abstract}

Conclusion: The extracts from I. obliquus, P. igniarius, C. sinensis, and M. esculenta showed potential anti-FIV activity.

Keywords: feline immunodeficiency virus, fluorescence spectroscopy, mushrooms, crude extracts, reverse transcriptase.

\section{Introduction}

Feline immunodeficiency virus (FIV) is a lentivirus which causes AIDS-like symptoms in domestic and wild cats and hyenas. The genome size of FIV is approximately 9400 base pairs, including pol, gag, and env genes. These genes are responsible for expressing three major functions of FIV proteins, which are virion structural proteins, reverse transcriptase, and viral envelope glycoprotein, respectively [1]. The infected cats suffer from other opportunistic diseases such as stomatitis, dermatitis and gingivitis, as well as neuropathological disorders and malignancy [2]. FIV infects T-cells, monocytes, macrophages, and neural cells by binding to the CD134 receptor and CXCR4 coreceptor. After viral entry, its single-stranded RNA

Copyright: Seetaha, et al. Open Access. This article is distributed under the terms of the Creative Commons Attribution 4.0 International License (http://creativecommons.org/licenses/ by/4.0/), which permits unrestricted use, distribution, and reproduction in any medium, provided you give appropriate credit to the original author(s) and the source, provide a link to the Creative Commons license, and indicate if changes were made. The Creative Commons Public Domain Dedication waiver (http:// creativecommons.org/publicdomain/zero/1.0/) applies to the data made available in this article, unless otherwise stated. genome is converted into proviral double-stranded DNA by FIV reverse transcriptase (FIV-RT) enzyme before integrating into the host genome [1]. Therefore, FIV-RT is a core enzyme in viral replication and infection. Treatment of FIV-infected cats could be performed by inhibiting FIV-RT, for example, the use of nucleotide analog or non-nucleoside reverse transcriptase inhibitors $[3,4]$.

FIV-RT is a heterodimeric protein consisting of two subunits, p51 and p66. The p66 subunit contains N-terminal RNA-dependent DNA polymerase (RDDP) and C-terminal RNaseH domains, while the p51 subunit contains only RDDP domain. The RDDP domain of both subunits contains four subdomains which are fingers, palm, thumb, and connection, but the arrangement of these subdomains is different [5]. The inhibition of RT has mainly focused on the catalytic site on the RDDP domain of p66 and the non-nucleotide binding pocket (NNBP) which is located approximately $10 \AA$ from the catalytic site. Two types of drugs have been used to inhibit FIV-RT by binding to these pockets. The first type of inhibitors is nucleotide analog or nucleoside analog reverse 
transcriptase inhibitors (NtARTIs or NARTIs). These inhibitors are widely used as antiviral drugs to treat viral infections in both human and cats. They share structural similarities to the natural substrates of the enzyme, therefore, both inhibitors bind at the active site of FIV-RT. Zidovudine (3'-azido-2',3'-dideoxythymidine or AZT) was the first antiviral drug used to treat HIV infection in humans, and it was then applied to cure FIV infection in cats [3]. In human, $1-5 \mathrm{mg} /$ $\mathrm{kg}$ AZT was injected intravenously every $4-8 \mathrm{~h}$ for 2 weeks, and then, $2-10 \mathrm{mg} / \mathrm{kg}$ AZT was given orally for another 2 weeks. All doses used could elevate number of helper-inducer lymphocyte and patient's weight [6]. In cats, AZT could inhibit FIV replication in CrandellRees feline kidney cells and could improve the clinical status of the infected cats [4,7]. Application of AZT on infected cats at a dose of $2.5 \mathrm{mg} / \mathrm{kg}$ of body weight every $12 \mathrm{~h}$ for 3 weeks could improve general clinical status and CD4/CD8 ratio at average degrees of 0.6 and 0.2 , respectively [7]. Although AZT could inhibit FIV replication in vitro and could improve the CD4/CD8 ratio, long-term treatment of FIV infection in cats could cause FIV mutation [8]. Moreover, the viral load was slightly increased in some cats after discontinuing the treatment [8]. Other NARTIs introduced to treat FIV-infected cats were 9-(2-phosphonylmethoxyethyl) adenine (PMEA) which showed more potent anti-FIV-RT activity than AZT. However, PMEA showed more severe side effects than AZT, which limits the use of PMEA for the treatment of FIV infection in cats [7]. The second type of antiviral drug is non-nucleoside reverse transcriptase inhibitors (NNRTIs). NNRTIs are hydrophobic compounds with diverse structures [9]. The binding of NNRTIs at the NNBP, which is located in close proximity to the active site, causes conformational change of the catalytic site leading to inhibition of viral replication [10]. Nevirapine, is one of the FDA-approved NNRTIs anti-HIV drugs, has shown to be ineffective against FIV [11]. Thus, the finding of new NNRTIs against FIV-RT will be a major breakthrough for the treatment of FIV-infected cats.

Recently, researchers have become interested in using mushrooms as a source of biologically active compounds for medical uses such as anticancer, antiviral, immunomodulating, as well as hepatoprotective agents [12-15]. Hispolon, a bioactive compound isolated from Inonotus obliquus, was found to be a potential anti-oral cancer. It could suppress cell proliferation of human epidermoid KB cell with a $50 \%$ inhibitory concentrations $\left(\mathrm{IC}_{50}\right)$ value of $4.62 \pm 0.16$ $\mu \mathrm{g} / \mathrm{mL}$ [12]. Ganoderic acid $\alpha$, ganoderiol $\mathrm{F}$, and ganodermanontriol from Ganoderma lucidum showed anti-HIV-1 activity by inhibiting HIV-1-induced cytopathic effects and HIV-1 protease [13]. $\beta$-Glucan from Grifola frondosa and Lentinus lepideus showed immunomodulating activities such as promoting mouse bone marrow cell growth and differentiating and increasing the number of granulocytes and myeloid progenitors [14]. The crude extracts from $G$. frondosa and Lentinula edodes can reduce the level of serum transaminases, which were produced from injured liver cells from paracetamol [15]. Thus, mushrooms are an excellent source of promising pharmaceutical agents.

In this study, the extracts of 17 medicinal and edible mushrooms were screened for anti-FIV-RT properties. The objective of this study was to determine the anti-FIV potential of some mushrooms.

\section{Materials and Methods}

\section{Ethical approval}

This work was approved by the Research Committee of Kasetsart University and Maejo University Phrae Campus and was performed under project ID of MJU. 2-61-009.

\section{Study period and location}

The study was performed at Faculty of Veterinary Medicine and Faculty of Science, Kasetsart University from January to July 2019.

\section{Chemicals}

All chemicals used were of analytical grade except ethanol and hexane, which were of reagent grade. The EnzChek ${ }^{\circledR}$ Reverse Transcriptase Assay Kit was purchased from Molecular Probes (USA). Efavirenz (EFV) was from the Government Pharmaceutical Organization (GPO) (Thailand).

\section{Cloning, expression, and purification of FIV-RT}

The amino acid sequence of FIV-RT from PDB ID 5OVN was used to design its corresponding DNA sequence. As FIV-RT is a heterodimeric protein containing $\mathrm{p} 66$ and $\mathrm{p} 51$ subunits in which $\mathrm{p} 51$ is produced from proteolytic processing of $\mathrm{p} 66$, the amino acid sequence of p66 was used to generate the DNA sequence by submitting to the GenScript Express Gene Synthesis Service (GenScript, USA). Codon optimization was also performed to ensure high-protein expression in Escherichia coli. The fiv-rt gene was synthesized and cloned into $\mathrm{pET} 15 \mathrm{~b}$ at NdeI and XhoI restriction sites and the new recombinant plasmid was named pET15b_FIV-RTp66. For cloning of p51, the primers were designed with NdeI and XhoI restriction sites, and pET15b_FIV-RTp66 was used as a template. PCR reaction was performed with 5'ATTCATATGGCGCAGATTAGCG3' forwardprimer and 5'ATCTCGAGTTATTTAATGTTCAGCG3' reverse primer. The DNA fragment of p51 was also cloned into the pColdI vector at the same restriction sites. The recombinant plasmids containing fiv-rtp51 genes were named pClodI_FIV-RTp51. Each plasmid was individually transformed into E. coli $\mathrm{DH} 5 \alpha$ and BL21 (DE3) for maintaining DNA stock and protein expression, respectively. The FIV-RT subunits p51 and p66 were individually expressed in $1 \mathrm{~L}$ of LB broth containing $0.5 \mathrm{mM}$ IPTG at $180 \mathrm{rpm}, 16^{\circ} \mathrm{C}$ for $16-18$ $\mathrm{h}$. Then, the induced cells were harvested and pooled together before subjecting to protein purification using ultrasonication for cell lysis and using Ni-Sepharose and 
Resource S cation exchange chromatography for protein purification [16]. After protein purification, the heterodimer of FIV-RT (p66/p51) was obtained for further inhibitory assays.

\section{Mushroom samples and preparation of crude mush- room extracts}

The fruiting bodies and mycelium of 17 edible and medicinal mushrooms, namely, Agaricus blazei, Dictyophora indusiata, G. lucidum, Hericium erinaceus, Hypsizygus marmoreus, I. obliquus, Lentinus squarrosulus, L. edodes, Lentinus TAFRS007, Lentinus TAFRS011, Lentinus TAFRS014, Morchella esculenta, Cordyceps sinensis, Pleurotus sajor-caju, Pleurotus eryngii, Phellinus igniarius, and Tremella fuciformis were collected from local markets in Thailand. The fruiting bodies or mycelia were cut into small pieces, ground, and lyophilized for 2 days. Then, the dried small pieces of mushrooms were ground into powder and divided into three parts. Each part was extracted with each solvent, distilled water (DW), and $99.5 \%$ ethanol and hexane. Ethanol and hexane extractions were carried out by incubating at $37^{\circ} \mathrm{C}$ in a shaker at $180 \mathrm{rpm}$ overnight, while the DW extraction was performed at $25^{\circ} \mathrm{C}$ overnight in a shaker at the same rpm. After that, all crude extracts were filtered through Whatman no.1 filters and centrifuged at $7000 \mathrm{rpm}, 4^{\circ} \mathrm{C}$ for $15 \mathrm{~min}$ to remove precipitate. The ethanol and hexane solvents were removed using a hot air oven at $80^{\circ} \mathrm{C}$, and the DW was removed by lyophilization. The mushroom powder was redissolved in $100 \%$ dimethyl sulfoxide (DMSO) to a final concentration of $100 \mathrm{mg} / \mathrm{mL}$. The crude extracts were kept at $-20^{\circ} \mathrm{C}$ until used.

\section{Relative inhibition assay}

EnzChek ${ }^{\circledR}$ reverse transcriptase assay kit (Molecular Probes, USA) was used in this study. The relative inhibition assay was performed using fluorescence spectroscopy as previously described [17]. Briefly, $2 \mu \mathrm{L}$ of $10 \mathrm{mg} / \mathrm{mL}$ crude mushroom extract was added into each well of a 384-well plate containing $13 \mu \mathrm{L}$ RT reaction buffer $(50 \mathrm{mM}$ TE $\mathrm{pH} 7.6,2$ $\mathrm{mM}$ DTT, $20 \%$ glycerol). Then, $5 \mu \mathrm{L}$ of $50 \mathrm{nM}$ purified recombinant wild-type FIV-RT was added into each well. The reaction was started by adding $5 \mu \mathrm{L}$ of 1:400 primer/template substrate. The reaction was incubated at $25^{\circ} \mathrm{C}$ for $30 \mathrm{~min}$ and was stopped by adding $5 \mu \mathrm{L} 0.2 \mathrm{M}$ EDTA. After that, $40 \mu \mathrm{L}$ of 1:700 Picogreen was added to the stopped reaction. The reaction was then incubated in the dark for 5 min and fluorescence was measured at an excitation wavelength of $485 \mathrm{~nm}$ and an emission wavelength of $535 \mathrm{~nm}$. EFV was used instead of the mushroom extract for the positive control reaction. The reaction without inhibitor was used as a negative control. The relative inhibition was calculated using the formula: Relative inhibition $(\%)=\left[\left(\mathrm{FI}_{\mathrm{P}}-\mathrm{FI}_{\mathrm{S}}\right) \times 100\right] /$ $\mathrm{FI}_{\mathrm{p}}$, where $\mathrm{FI}_{\mathrm{p}}$ and $\mathrm{FI}_{\mathrm{S}}$ were fluorescence intensities of the positive control and mushroom reactions, respectively. Three independent experiments were performed. Mushrooms which showed relative inhibition higher than $70 \%$ were chosen for further $\mathrm{IC}_{50}$ assays.

\section{Determination of IC $_{50}$ values}

A two-fold serial dilution of the mushroom crude extract was performed and was then used as an inhibitor in $\mathrm{IC}_{50}$ assays. The $2 \mu \mathrm{L}$ of each two-fold diluted mushroom extract was mixed with $13 \mu \mathrm{L}$ RT reaction buffer in a 384-well plate. Then, $5 \mu \mathrm{L}$ of $50 \mathrm{nM}$ purified recombinant wild-type FIV-RT was added into each well. The reaction was started by adding $5 \mu \mathrm{L}$ of 1:400 primer/template. The reaction was incubated, stopped and the fluorescence intensity was measured as previously described. The $\mathrm{IC}_{50}$ was calculated from the non-linear regression dose-response curve generated by the GraphPad Prism program (GraphPad Software Inc., San Diego, CA, USA). The $\mathrm{IC}_{50}$ value of EFV against FIV-RT was also determined.

\section{Results}

\section{Cloning, expression, and purification of FIV-RT}

The amino acid sequence of FIV-RT from the PDB database under ID no. 5OVN was used for designing its corresponding DNA sequence. Codon optimization was also performed to ensure high-protein expression in the bacterial host. The DNA fragment of p66 was synthesized and cloned into the pET15b expression vector which was then used to generate a DNA fragment of p51. The p51 was also cloned into pColdI. Both subunits were individually transformed into E. coli BL21 (DE3) and expressed as intracellular His-tagged proteins. Purifications of both subunits were performed by combining IPTG-induced E. coli BL21 (DE3) cells harboring each construct before subjecting to sonication and Ni-Sepharose and Resource S cation chromatography. The final yield of purified recombinant wild-type FIV-RT was 8-10 mg from $1 \mathrm{~L}$ of culture medium. Each subunit of purified FIV-RT showed molecular weights of 66 and $51 \mathrm{kDa}$, respectively, on $12 \%$ SDS-PAGE as expected, and more than $90 \%$ purity of recombinant FIV-RT was obtained as judged by SDS-PAGE (Figure-1).

\section{Mushroom crude extracts}

The 17 mushrooms used in this study were collected from local distributors in Thailand and were extracted with three different solvents. Sixty-four crude mushroom extracts were obtained. Each mushroom extract was dissolved in $100 \%$ DMSO to a final concentration of $100 \mathrm{mg} / \mathrm{mL}$ and kept at $-20^{\circ} \mathrm{C}$ until used.

\section{Relative inhibition of FIV-RT}

To determine whether the purified recombinant wild-type FIV-RT was active or not, the activity of the enzyme was tested using the EnzCheck ${ }^{\circledR}$ Reverse Transcriptase Assay Kit. The different concentrations of the enzyme were reacted with substrate as described 


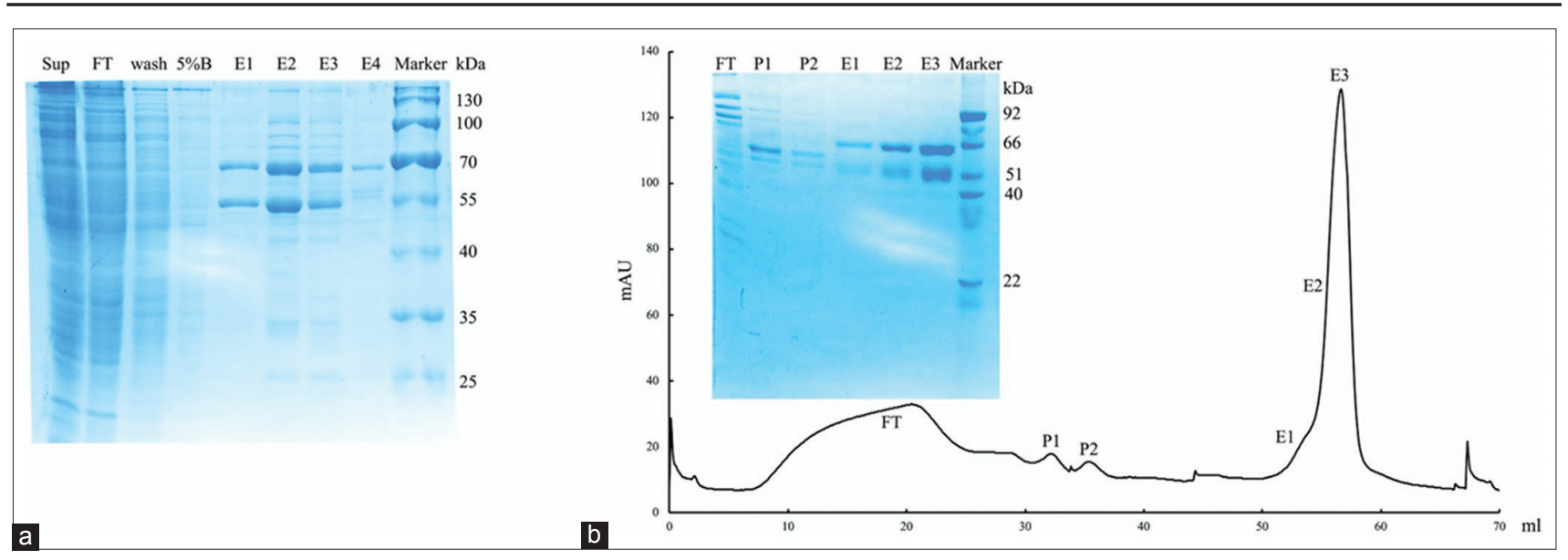

Figure-1: Purification of recombinant wild-type feline immunodeficiency virus reverse transcriptase. The enzyme was purified through $\mathrm{Ni}$-Sepharose and determined with 12\% SDS-PAGE (Sup=Supernatant, FT=Flow-through, Wash=Washed with buffer $A, 5 \% B=$ Washed with $5 \%$ buffer $B, E 1-E 4=E l u t e d$ fraction) (a). Then, resource S cation exchange chromatography was performed to obtained high purity protein and confirmed with $12 \%$ SDS-PAGE (FT=Flow-through, P1-P2=Peaks from $0 \%$ to $15 \%$ gradient buffer B, E1-E3=Elution peaks from $15 \%$ to $35 \%$ gradient buffer B) (b).

in the relative inhibition assay. The results showed that enzyme concentrations up to $15 \mathrm{nM}$ were linearly proportional to relative fluorescence unit. Thus, the enzyme concentration at $10 \mathrm{nM}$ was used in the subsequent experiments (Figure-2). The relative inhibition of FIV-RT by crude mushroom extracts was performed by incubating $0.8 \mathrm{mg} / \mathrm{mL}$ of each mushroom extract with $10 \mathrm{nM}$ purified recombinant wild-type FIV-RT. Crude mushrooms extracts showed various inhibition activities against FIV-RT (Figure-3). The DW extracts of fresh fruiting bodies of L. edodes, Lentinus TAFRS011, M. esculenta, $C$. sinensis, P. eryngii, P. sajor-caju, and dried mycelium of I. obliquus; ethanol extracts of fresh fruiting bodies of $H$. marmoreus, L. edodes, L. squarrosulus, P. eryngii, and dried mycelium of Lentinus TAFRS011; and hexane extracts of fresh fruiting bodies of $H$. marmoreus and $P$. sajorcaju showed no inhibition activity against FIV-RT. The extracts which showed relative inhibition higher than $70 \%$ were selected for $\mathrm{IC}_{50}$ assay. Thus, the DW extracts of fresh fruiting bodies of H. marmoreus and P. igniarius and fresh mycelium of I. obliquus; ethanol extracts of fresh fruiting bodies of G. lucidum, M. esculenta, $C$. sinensis, P. igniarius, and T. fuciformis, dried fruiting bodies and fresh mycelium of I. obliquus, and dried mycelium of Lentinus TAFRS014; and hexane extracts of fresh fruiting bodies of L. edodes, M. esculenta, $C$. sinensis, and P. igniarius, dried fruiting bodies of A. blazei and I. obliquus and dried mycelia of I. obliquus and Lentinus TAFRS011 were selected for further study.

\section{IC $_{50}$ value}

The determination of the $\mathrm{IC}_{50}$ of crude mushroom extracts against FIV-RT was performed with the final concentrations of the extracts ranging from $0.012 \mu \mathrm{g} / \mathrm{mL}$ to $26 \mathrm{mg} / \mathrm{mL}$, and the results are shown in Table-1 and Figure-4. The ethanol extract of dried fruiting bodies of I. obliquus showed the strongest anti-FIV-RT activity with an $\mathrm{IC}_{50}$ value of

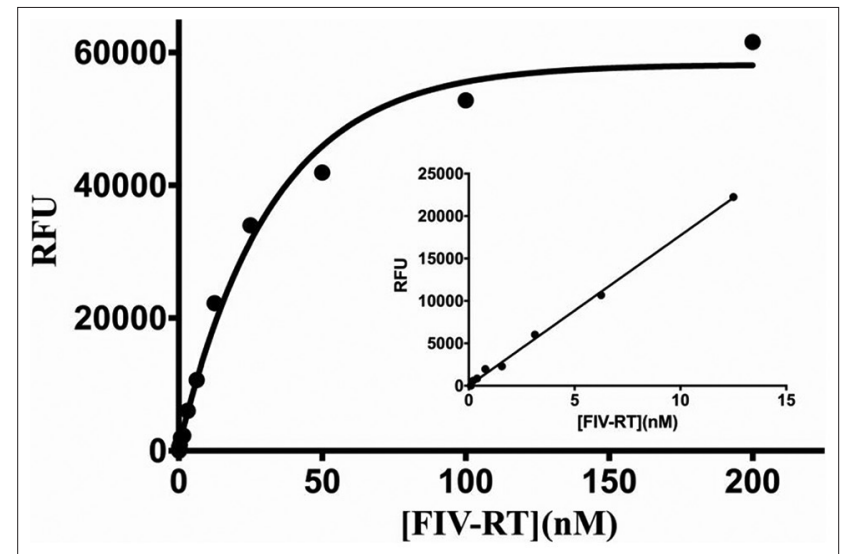

Figure-2: Feline immunodeficiency virus reverse transcriptase (FIV-RT) activity determination. The activity of different concentrations of purified recombinant wildtype FIV-RT was tested using the EnzChek ${ }^{\circledR}$ reverse transcriptase assay kit. A $10 \mathrm{nM}$ of FIV-RT was used in the subsequent inhibition assays.

$0.80 \pm 0.16 \mu \mathrm{g} / \mathrm{mL}$, while its hexane extract showed an $\mathrm{IC}_{50}$ value of $1.22 \pm 0.20 \mu \mathrm{g} / \mathrm{mL}$. Other crude mushroom extracts, such as ethanol and DW extracts of P. igniarius, ethanol extract of fresh fruiting bodies of $C$. sinensis, hexane extract of dried mycelium of I. obliquus, ethanol extract of fresh fruiting bodies of $G$. lucidum, and hexane extracts of fresh fruiting bodies of $M$. esculenta and $C$. sinensis also exhibited strong inhibition against FIV-RT (Table-1). However, the $\mathrm{IC}_{50}$ values of these mushroom extracts were lower than that of EFV, which was $0.019 \pm 0.002 \mu \mathrm{g} / \mathrm{mL}$. The hexane extract of fresh fruiting bodies of $P$. igniarius showed the weakest anti-FIV-RT activity with an $\mathrm{IC}_{50}$ value of $1.630 \pm 251.03 \mu \mathrm{g} / \mathrm{mL}$.

\section{Discussion}

FIV causes AIDS-like symptoms in cats. The infected cats suffer from various opportunistic infectious diseases. Moreover, FIV infection is persistent and lifelong treatment is required which will be costly 


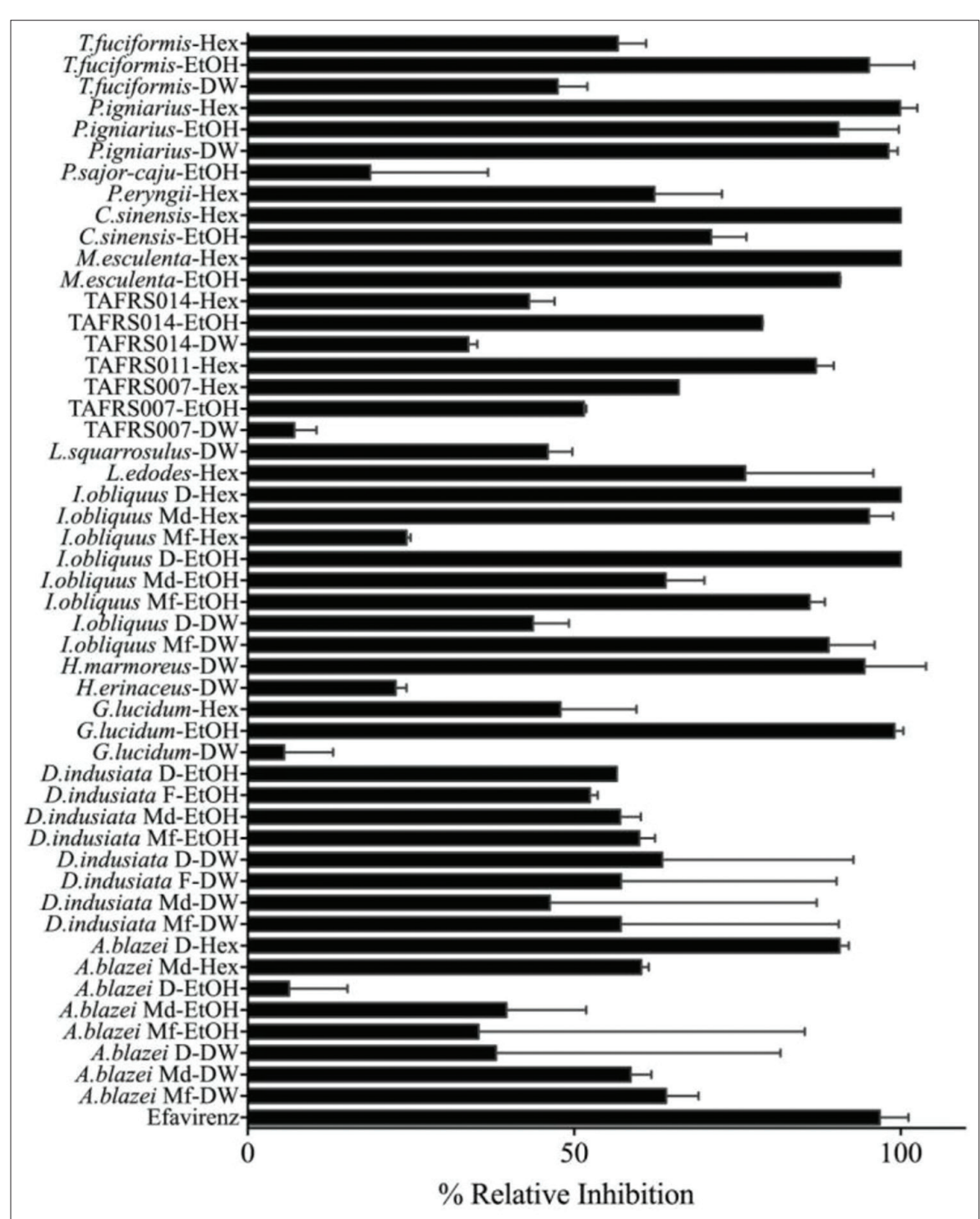

Figure-3: Relative inhibition of mushroom crude extracts. A final concentration of $0.8 \mathrm{mg} / \mathrm{mL}$ of each mushroom extracts was used.

Table-1: $\mathrm{IC}_{50}$ of crude mushroom extracts compared with efavirenz.

\begin{tabular}{lc}
\hline Sample & IC $_{\mathbf{5 0}}(\boldsymbol{\mu g} / \mathbf{m L})$ \\
\hline Efavirenz & $0.019 \pm 0.002$ \\
Agaricus blazei D-Hex & $502.60 \pm 126.82$ \\
Ganoderma lucidum-EtOH & $65.37 \pm 14.14$ \\
Hypsizygus marmoreus-Hex & $715.60 \pm 257.97$ \\
Inonotus obliquus Mf-DW & $852.80 \pm 350.56$ \\
Inonotus obliquus Mf-EtOH & $391.70 \pm 127.50$ \\
Inonotus obliquus D-EtOH & $0.80 \pm 0.16$ \\
Inonotus obliquus Md-Hex & $49.97 \pm 11.86$ \\
Inonotus obliquus D-Hex & $1.22 \pm 0.20$ \\
Lentinula edodes-Hex & $477.80 \pm 132.08$ \\
TAFRS011-Hex & $1.727 \pm 442.04$ \\
TAFRS014-EtOH & $317.20 \pm 66.72$ \\
Morchella esculenta-EtOH & $211.90 \pm 64.25$ \\
Morchella esculenta-Hex & $77.59 \pm 8.31$ \\
Cordyceps sinensis-EtOH & $29.73 \pm 12.39$ \\
Cordyceps sinensis-Hex & $81.41 \pm 17.10$ \\
Phellinus igniarius-DW & $6.24 \pm 1.42$ \\
Phellinus igniarius-EtOH & $4.33 \pm 0.39$ \\
Phellinus igniarius-Hex & $1630.00 \pm 251.03$ \\
Tremella fuciformis-EtOH & $623.70 \pm 253.64$ \\
\hline IC
\end{tabular}

$\mathrm{IC}_{50}=50 \%$ Inhibitory concentrations for the cat owners. The use of human anti-HIV drugs showed a promising result; however, it showed some limitations such as drug side effects, reappearance of virus after discontinuing treatment, and occurrence of mutant FIV $[7,8]$. Thus, it is necessary to search for new medicine to treat the infected cats. Mushrooms have gained more attention in the past few years due to their abundance of bioactive compounds [12-15]. In this study, 17 mushrooms were chosen to screen for anti-FIV-RT activity.

Cloning, expression, and purification through Ni-Sepharose and resource S cation exchange chromatography yielded an active dimeric FIV-RT, which was then used for screening of anti-FIV-RT agents. The inhibition studies revealed that the extracts from I. obliquus showed strong inhibitory activity against FIV-RT with $\mathrm{IC}_{50}$ values of $0.80 \pm 0.16$ and $1.22 \pm 0.20 \mu \mathrm{g} / \mathrm{mL}$ for I. obliquus D-EtOH and I. obliquus D-Hex, respectively. I. obliquus is classified as a medicinal mushroom and has been used in traditional medicine for the prophylaxis and treatment

Veterinary World, EISSN: 2231-0916 


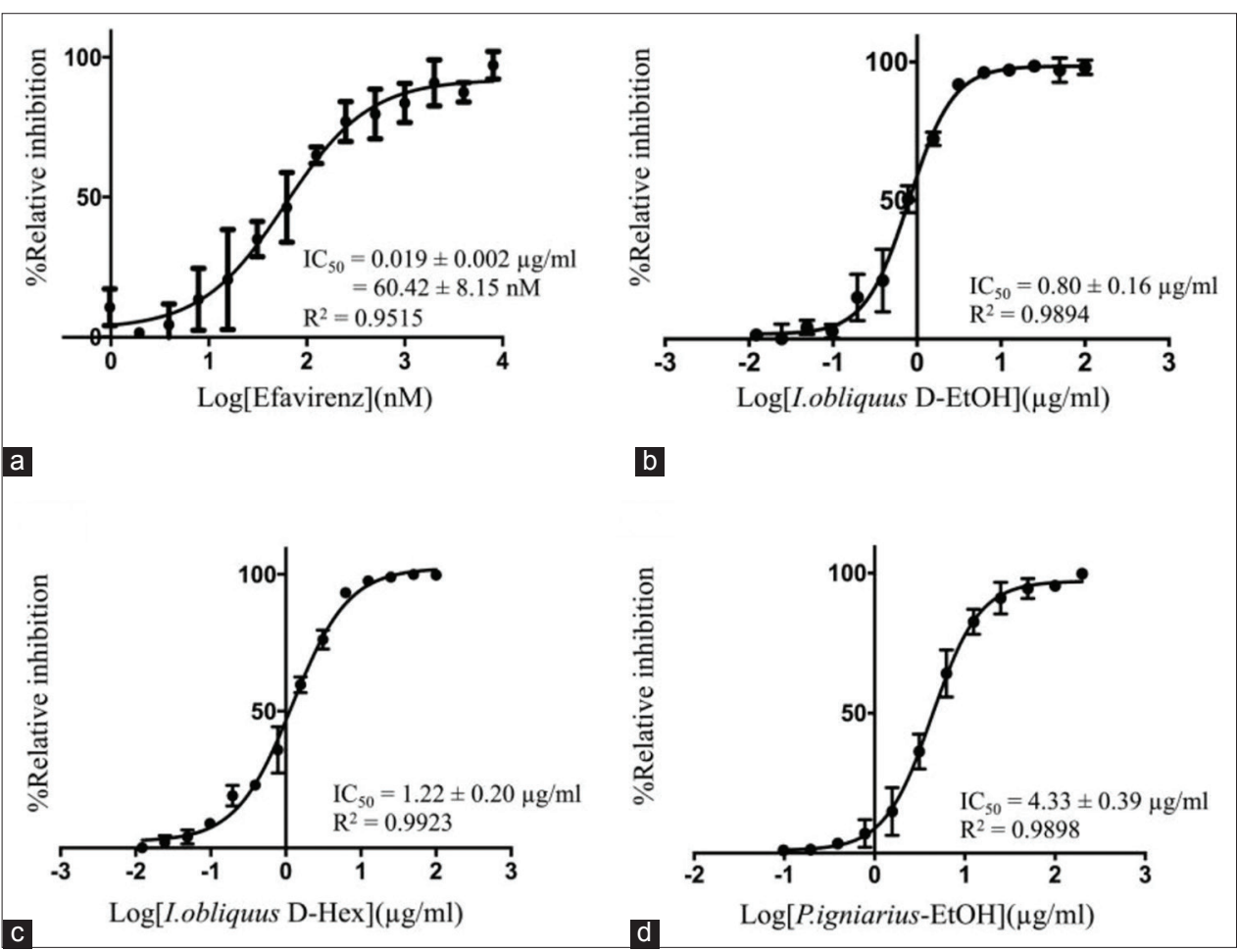

Figure-4: (a-d) The $50 \%$ inhibitory concentrations values of crude mushroom extracts which showed strong inhibitory activity against feline immunodeficiency virus reverse transcriptase.

of various diseases such as gastric disorder, diabetes mellitus, cancers, cardiovascular, and viral infection diseases [12,18-25]. The water/ethanol extract of $I$. obliquus showed anti-herpes simplex virus (HSV) type 1 activity in infected Vero cells [21,22]. The extract showed the $\mathrm{IC}_{50}$ of 3.82 and $12.29 \mu \mathrm{g} /$ $\mathrm{mL}$ in the plaque reduction and $\mathrm{HSV}-1 /$ blue assays, respectively [21]. The $5 \mu \mathrm{g} / \mathrm{mL}$ rate of I. obliquus extract could protect the infected cells from HSVinduced cytodestruction. The best protective effect was observed when I. obliquus extracts were added before or within $1 \mathrm{~h}$ after HSV infection [22]. The mechanism of anti-HSV was found to be at the initial stage of viral infection by inhibiting membrane fusion between HSV and Vero cells. In addition, I. obliquus extract showed anti-hepatitis $C$ virus, human influenza viruses $\mathrm{A}$ and $\mathrm{B}$, and human immunodeficiency virus type 1 activity in cell-based assays [20,23]. Chemical analysis of the methanol extract of I. obliquus revealed that it contains protocatechuic acid which has been shown to have antioxidant, antibacterial, antiviral, and immune regulating activities [19]. Moreover, Tian et al. [24] stated that polysaccharides from $I$. obliquus (IOPs) could act as a broad-spectrum antiviral drug against feline calicivirus, feline herpesvirus 1 , feline influenza virus $\mathrm{H} 3 \mathrm{~N} 2$ and $\mathrm{H} 5 \mathrm{~N} 6$, feline panleukopenia virus, and feline infectious peritonitis virus by blocking viral binding/absorption and replication. From these studies, the bioactive compounds responsible for anti-FIV-RT activity in I. obliquus extract might be protocatechuic acid or IOPs. The solvents and methods used to obtain the extracts from mushrooms could affect the chemical constituents in the extracts [19]. Therefore, it is mandatory that further studies will be performed to clarify whether these compounds or other specific components are responsible for anti-FIV-RT property of I. obliquus.

The extracts from $P$. igniarius also exhibited strong anti-FIV-RT activity with the $\mathrm{IC}_{50}$ values of $4.33 \pm 0.39 \mu \mathrm{g} / \mathrm{mL}$ and $6.24 \pm 1.42 \mu \mathrm{g} / \mathrm{mL}$ for $P$. igniarius-EtOH and P. igniarius-DW, respectively. P. igniarius is also classified as a medicinal mushroom and is one of the most used mushrooms in Asian folk medicine to treat many diseases, including cancers. Lee et al. [26] reported that the water extract of $P$. igniarius had antiviral activity against influenza $\mathrm{A}$ and $\mathrm{B}$, including pandemic $\mathrm{H} 1 \mathrm{~N} 1$, human $\mathrm{H} 3 \mathrm{~N} 2$, avian $\mathrm{H} 9 \mathrm{~N} 2$, and oseltamivir-resistant $\mathrm{H} 1 \mathrm{~N} 1$ viruses by blocking virus attachment to the cell surface receptor. Lee et al. also speculated that its polysaccharides might be responsible for the antiviral activity as they are the main components of the mushroom extracts [26]. The water extract of $P$. igniarius also showed anti-HSV-1 activity in Vero cells [27]. The study of the chemical composition revealed that the mushroom contains hispidin, which showed anti-influenza viruses H1N1 and H3N2 and anti-HIV-1 integrase activity. Hispidin is of interest to use in drug discovery [28]. Again, it is necessary that further studies be performed to evaluate the effect of hispidin on FIV-RT activity and search for novel active compounds against FIV-RT.

The extracts of G. lucidum, M. esculenta, and C. sinensis also showed good anti-FIV-RT activity. They could inhibitFIV-RT at a similar strength $\left(\mathrm{IC}_{50}\right.$ values ranging from $29.73 \pm 12.37$ to $81.41 \pm 17.10 \mu \mathrm{g} / \mathrm{mL}$, which were approximately 10 -fold higher $\mathrm{IC}_{50}$ values 
Table-2: Possible bioactive substances, potential activity, and toxic effect in mushroom used in this study.

\begin{tabular}{|c|c|c|c|c|}
\hline Mushroom & Bioactive substance & Potential activity & Toxic effect & References \\
\hline $\begin{array}{l}\text { Cordyceps } \\
\text { sinensis }\end{array}$ & Cordycepin & $\begin{array}{l}\text { Anti-herpes simplex virus type-1 } \\
\text { activity in Vero cells }\end{array}$ & $0.0005 \mu \mathrm{M}$ & [32] \\
\hline \multirow[t]{5}{*}{ Inonotus obliquus } & Hispolon & $\begin{array}{l}\text { Inhibition of human epidermoid KB } \\
\text { cell proliferation }\end{array}$ & $\mathrm{IC}_{50}=4.62 \mu \mathrm{g} / \mathrm{mL}$ & [12] \\
\hline & $\begin{array}{l}\text { Inonotusol G } \\
\text { Protocatechuic aldehyde } \\
\text { 4-(3,4-Dihydroxyphenyl) } \\
\text { but-3en-2-one } \\
\text { 5-fluorouracil }\end{array}$ & $\begin{array}{l}\text { Cytotoxicity against BEL7402, A-549, } \\
\text { and KB human cell lines }\end{array}$ & $\mathrm{IC}_{50}=3.1-9.9 \mu \mathrm{g} / \mathrm{mL}$ & [25] \\
\hline & Protocatechuic acid & Antivirus & & [37] \\
\hline & Polysaccharide & $\begin{array}{l}\text { Anti-virus against feline herpes } \\
\text { virus, feline influenza virus, feline } \\
\text { panleukopenia virus, and feline } \\
\text { infectious peritonitis virus }\end{array}$ & $\mathrm{IC}_{50}=18.15-68.47 \mu \mathrm{g} / \mathrm{mL}$ & [24] \\
\hline & Polysaccharide & Anti-HIV-1 protease & $\mathrm{IC}_{50}=2.5 \mu \mathrm{g} / \mathrm{mL}$ & [29] \\
\hline \multirow{2}{*}{ Phellinus igniarius } & Hispidin & Anti-HIV-1 integrase & $2 \mu \mathrm{M}$ & [27] \\
\hline & Phelligridin D & $\begin{array}{l}\text { Antiviral activity against influenza A } \\
\text { virus H1N1 in MDCK cells }\end{array}$ & $\mathrm{IC}_{50}=24.6 \mu \mathrm{M}$ & {$[38]$} \\
\hline \multirow[t]{2}{*}{$\begin{array}{l}\text { Ganoderma } \\
\text { lucidum }\end{array}$} & Ganoderiol F & $\begin{array}{l}\text { Inhibition of HIV-1-induced } \\
\text { cytopathic effect in MT- } 4 \text { cells }\end{array}$ & $7.8 \mu \mathrm{g} / \mathrm{mL}$ & [29] \\
\hline & Ganoderic acid B & Anti-HIV-1 protease & $0.17 \mathrm{mM}$ & [29] \\
\hline
\end{tabular}

than those of I. obliquus and P. igniarius). The extract of G. lucidum showed a broad spectrum of antiviral activity against various viruses such as Enterovirus 71, hepatitis B virus, HIV-1, HSV-1, and vesicular stomatitis virus. These antiviral activities were mainly from polysaccharides and triterpenes [29]. C. sinensis and $M$. esculenta also exhibited wide range of pharmacological properties including antiviral, antimicrobial, antioxidant, antitumor, anti-inflammatory, and immune regulation [30]. Research on the antiviral activity of $C$. sinensis, has been conducted. In addition, Ohta et al. [31] found that acidic polysaccharide (APS) extracted from Cordyceps militaris could reduce influenza A titer in infected mice. APS could also modulate the immune function of macrophages and increase mice survival rate. Cordycepin, adenosine analog (3'-deoxyadenosine), and its derivatives showed anti-influenza, plant, HIV, murine leukemia, and Epstein-Barr viruses activity [32,33]. In the case of $M$. esculenta, the study on antiviral activity of this mushroom is limited. To the best of our knowledge, antiviral activity of $M$. esculenta has not been previously reported. This study was the first on the antiviral property of $M$. esculenta extract. Further research is also required to separate and identify bioactive compounds responsible for anti-FIV-RT properties.

Comparison of the $\mathrm{IC}_{50}$ values of these mushroom extracts and anti-HIV drug EFV revealed that the $\mathrm{IC}_{50}$ values of mushroom extracts were much higher than that of EFV. However, this study clearly showed the anti-FIV potential of these mushroom extracts through inhibition of the RT enzyme which is important for viral infection. Further study is needed to investigate whether the anti-FIV activity is due to a specific component or the combined effect of various individual constituents. As mushroom extracts have been shown to possess antioxidant activity, they can be used as a tonic to reduce oxidative stress during acute FIV infection [34]. Moreover, mushrooms have been reported to show immunomodulating activity. They could be used in combination with drugs to initiate and support immune responses [31,35]. Synergism between a mushroom extract and antiviral drug has also been reported [36]. It is noteworthy that extraction with nonpolar solvents (hexane and ethanol) gave extracts with great inhibitory activity against FIV-RT. The chemical constituents in these extracts might be hydrophobic compounds. NNRTIs are small hydrophobic molecules with diverse structures. Thus, these mushroom extracts may contain novel NNRTIs. The water extract also showed good anti-FIV-RT activity. It has been reported that some proteins and polysaccharides extracted from mushrooms showed antiviral potential [12,24,25,27,29,31,32,35,37,38] (Table-2). Thus, the experimental design to obtain the anti-FIV compounds (e.g., type of inhibitor, solvent used, and purification method) should be taken into account in further studies and clinical applications.

\section{Conclusion}

A total of 17 medicinal and edible mushrooms widely distributed in Thailand were chosen to screen for anti-FIV-RT activity. Comparison of the inhibition potentials of these mushrooms against FIV-RT revealed that the ethanol extract from dried fruiting bodies of I. obliquus showed the strongest inhibition activity with an $\mathrm{IC}_{50}$ value of $0.80 \pm 0.16 \mu \mathrm{g} / \mathrm{mL}$. The hexane extract from dried mycelium of I. obliquus and ethanol and water extracts from fresh fruiting bodies of $P$. igniarius also exhibited strong activities with the $\mathrm{IC}_{50}$ values of $1.22 \pm 0.20,4.33 \pm 0.39$, and $6.24 \pm 1.42 \mu \mathrm{g} / \mathrm{mL}$, respectively. The ethanol extract from fresh fruiting bodies of $C$. sinensis, hexane extract from dried mycelium of $I$. obliquus and fresh fruiting bodies of G. lucidum, and the hexane extract 
of fresh fruiting bodies of $M$. esculenta and $C$. sinensis showed moderate anti-FIV-RT activities with $\mathrm{IC}_{50}$ values of $29.73 \pm 12.39,49.97 \pm 11.86,65.37 \pm 14.14$, $77.59 \pm 8.31$, and $81.41 \pm 17.10 \mu \mathrm{g} / \mathrm{mL}$, respectively. These mushroom extracts show anti-FIV potential. However, further study is required to identify the specific constituents responsible for anti-FIV-RT activity and their mechanism of action. In addition, the studies on the immune effect and interaction between mushroom extracts and anti-FIV drug candidates are also required for its clinical application.

\section{Authors' Contributions}

JR: Principle investigator, designed the study, drafted and critically revised the manuscript. KhCh: A research coordinator, performed cloning of FIV-RT and inhibition experiments, drafted and critically revised the manuscript. SS performed expression and purification of FIV-RT and sample collection, drafted and revised the manuscript. $\mathrm{KC}$ participated in design of the study and interpretation of the data. SR and LT performed mushroom extraction. All authors read and approved the final manuscript.

\section{Acknowledgments}

This work was financially supported from Faculty of Veterinary Medicine and the Center for Advanced Studies for Agriculture and Food, Institute for Advanced Studies, Kasetsart University Under the Higher Education Research Promotion and National Research University Project of Thailand, Office of the Higher Education Commission, Ministry of Education, Thailand and Center for Advanced Studies for Agriculture and Food, KU Institute for Advanced Studies, Kasetsart University, Bangkok 10900, Thailand (CASAF-PD024, NRU-KU, Thailand).

\section{Data Availability}

Supplementary data can be available from the corresponding author.

\section{Competing Interests}

The authors declare that they have no competing interests.

\section{Publisher's Note}

Veterinary World remains neutral with regard to jurisdictional claims in published institutional affiliation.

\section{References}

1. Kenyon, J.C. and Lever, A.M. (2011) The molecular biology of feline immunodeficiency virus (FIV). Viruses, 3(11): 2192-2213.

2. Magden, E., Quackenbush, S.L. and VandeWoude, S. (2011) FIV associated neoplasms--a mini-review. Vet. Immunol. Immunopathol., 143(3-4): 227-234.

3. Hartmann, K., Wooding, A. and Bergmann, M. (2015) Efficacy of antiviral drugs against feline immunodeficiency virus. Vet. Sci., 2(4): 456-476.

4. North, T.W., North, G.L. and Pedersen, N.C. (1989) Feline immunodeficiency virus, a model for reverse transcriptase-targeted chemotherapy for acquired immune deficiency syndrome. Antimicrob. Agents Chemother., 33(6): 915-919.

5. Galilee, M. and Alian, A. (2018) The structure of FIV reverse transcriptase and its implications for non-nucleoside inhibitor resistance. PLoS Pathog., 14(1): e1006849.

6. Yarchoan, R., Klecker, R.W., Weinhold, K.J., Markham, P.D., Lyerly, H.K., Durack, D.T., Gelmann, E., Lehrman, S.N., Blum, R.M. and Barry, D.W. (1986) Administration of 3'-azido-3'-deoxythymidine, an inhibitor of HTLV-III/LAV replication, to patients with AIDS or AIDS-related complex. Lancet, 1(8481): 575-580.

7. Hartmann, K., Donath, A., Beer, B., Egberink, H.F., Horzinek, M.C., Lutz, H., Hoffmann-Fezer, G., Thum, I. and Thefeld, S. (1992) Use of two virustatica (AZT, PMEA) in the treatment of FIV and of FeLV seropositive cats with clinical symptoms. Vet. Immunol. Immunopathol., 35(1-2): 167-175.

8. de Oliveira Medeiros, S., Abreu, C.M., Delvecchio, R., Ribeiro, A.P., Vasconcelos, Z., de Moraes Brindeiro, R. and Tanuri, A. (2016) Follow-up on long-term antiretroviral therapy for cats infected with feline immunodeficiency virus. J. Feline Med. Surg., 18(4): 264-272.

9. Usach, I., Melis, V. and Peris, J.E. (2013) Non-nucleoside reverse transcriptase inhibitors: A review on pharmacokinetics, pharmacodynamics, safety and tolerability. J. Int. AIDS Soc., 16(1): 1-14

10. Das, K. and Arnold, E. (2013) HIV-1 reverse transcriptase and antiviral drug resistance. Part 2. Curr. Opin. Virol., 3(2): 119-128.

11. Auwerx, J., North, T.W., Preston, B.D., Klarmann, G.J., De Clercq, E. and Balzarini, J. (2002) Chimeric human immunodeficiency virus Type 1 and feline immunodeficiency virus reverse transcriptases: Role of the subunits in resistance/sensitivity to non-nucleoside reverse transcriptase inhibitors. Mol. Pharmacol., 61(2): 400-406.

12. Chen, W., He, F.Y. and Li, Y.Q. (2006) The apoptosis effect of hispolo $\mathrm{n}$ from Phellinus linteus (Berkeley and Curtis) Teng on human epidermoid KB cells. J. Ethnopharmacol., 105(1-2): 280-285.

13. El-Mekkawy, S., Meselhy, M.R., Nakamura, N., Tezuka, Y., Hattori, M., Kakiuchi, N., Shimotohno, K., Kawahata, T. and Otake, T. (1998) Anti-HIV-1 and anti-HIV-1-protease substances from Ganoderma lucidum. Phytochemistry, 49(6): 1651-1657.

14. Lull, C., Wichers, H.J. and Savelkoul, H.F. (2005) Antiinflammatory and immunomodulating properties of fungal metabolites. Mediators Inflamm., 2005(2): 63-80.

15. Ooi, V.E.C. (1996) Hepatoprotective effect of some edible mushrooms. Phytother. Res., 10(6): 536-538.

16. Seetaha, S., Yagi-Utsumi, M., Yamaguchi, T., Ishii, K., Hannongbua, S., Choowongkomon, K. and Kato, K. (2016) Application of site-specific spin labeling for NMR detecting inhibitor-induced conformational change of HIV-1 reverse transcriptase. ChemMedChem, 11(4): 363-366.

17. Silprasit, K., Thammaporn, R., Tecchasakul, S., Hannongbua, S. and Choowongkomon, K. (2011) Simple and rapid determination of the enzyme kinetics of HIV-1 reverse transcriptase and anti-HIV-1 agents by a fluorescence based method. J. Virol. Methods, 171(2): 381-387.

18. Xin, X., Qu, J., Veeraraghavan, V.P., Mohan, S.K. and Gu, K. (2019) Assessment of the gastroprotective effect of the chaga medicinal mushroom, Inonotus obliquus (Agaricomycetes), against the gastric mucosal ulceration induced by ethanol in experimental rats. Int. J. Med. Mushrooms, 21(8): 805-816.

19. Duru, K.C., Kovaleva, E.G., Danilova, I.G. and van der Bijl, P. (2019) The pharmacological potential and possible molecular mechanisms of action of Inonotus obliquus from preclinical studies. Phytother. Res., 33(8): 1966-1980.

20. Shibnev, V.A., Mishin, D.V., Garaev, T.M., Finogenova, N.P., Botikov, A.G. and Deryabin, P.G. (2011) Antiviral activity of 
Inonotus obliquus fungus extract towards infection caused by hepatitis C virus in cell cultures. Bull. Exp. Biol. Med., 151(5): 612-614.

21. Pan, H.H., Yu, X.T., Li, T., Wu, H.L., Jiao, C.W., Cai, M.H., Li, X.M., Xie, Y.Z., Wang, Y. and Peng, T. (2013) Aqueous extract from a chaga medicinal mushroom, Inonotus obliquus (higher basidiomycetes), prevents herpes simplex virus entry through inhibition of viral-induced membrane fusion. Int. J. Med. Mushrooms, 15(1): 29-38.

22. Polkovnikova, M.V., Nosik, N.N., Garaev, T.M., Kondrashina, N.G., Finogenova, M.P. and Shibnev, V.A. (2014) A study of the antiherpetic activity of the chaga mushroom (Inonotus obliquus) extracts in the Vero cells infected with the herpes simplex virus. Vopr.Virusol., 59(2): 45-48.

23. Shibnev, V.A., Garaev, T.M., Finogenova, N.P., Kalnina, L.B. and Nosik, D.N. (2015) Antiviral activity of aqueous extracts of the birch fungus Inonotus obliquus on the human immunodeficiency virus. Vopr. Virusol., 60(2): 35-38.

24. Tian, J., Hu, X., Wu, H. and Qu, L. (2017) Identification of Inonotus obliquus polysaccharide with broad-spectrum antiviral activity against multi-feline viruses. Int. J. Biol. Macromol., 95(16): 160-167.

25. Liu, D., Zhao, D., Pan, H.H., Kang, I., Yu, X.T., Wang, H.Q., Li, B.M., Xie, Y.Z. and Chen, R.Y. (2014) Chemical constituents from Inonotus obliquus and their bological activities. J. Nat. Prod., 77(1): 35-41.

26. Lee, S., Kim, J.I., Heo, J., Lee, I., Park, S., Hwang, M.W., Bae, J.Y., Park, M.S., Park, H.J. and Park, M.S. (2013) The anti-influenza virus effect of Phellinus igniarius extract. $J$. Microbiol., 51(5): 676-681.

27. Dogan, H.H., Karagoz, S. and Duman, R. (2018) In vitro evaluation of the antiviral activity of some mushrooms from Turkey. Int. J. Med. Mushrooms, 20(3): 201-212.

28. Lee, I.K. and Yun, B.S. (2011) Styrylpyrone-class compounds from medicinal fungi Phellinus and Inonotus spp., and their medicinal importance. J. Antibiot. (Tokyo), 64(5): 349-359.

29. Lindequist, U., Niedermeyer, T.H. and Julich, W.D. (2005) The pharmacological potential of mushrooms. Evid Based
Complement. Alternat. Med., 2(3): 285-299.

30. Liu, Y., Wang, J., Wang, W., Zhang, H., Zhang, X. and Han, C. (2015) The chemical constituents and pharmacological actions of cordyceps sinensis. Evid Based Complement. Alternat. Med., 2015: Article ID 575063.

31. Ohta, Y., Lee, J.B., Hayashi, K., Fujita, A., Park, D.K. and Hayashi, T. (2007) In vivo anti-influenza virus activity of an immunomodulatory acidic polysaccharide isolated from Cordyceps militaris grown on germinated soybeans. $J$. Agric. Food Chem., 55(25): 10194-10199.

32. de Julian-Ortiz, J.V., Galvez, J., Munoz-Collado, C., Garcia-Domenech, R. and Gimeno-Cardona, C. (1999) Virtual combinatorial syntheses and computational screening of new potential anti-herpes compounds. J. Med. Chem., 42(17): 3308-3314.

33. Muller, W.E., Weiler, B.E., Charubala, R., Pfleiderer, W., Leserman, L., Sobol, R.W., Suhadolnik, R.J. and Schroder, H.C. (1991) Cordycepin analogues of 2',5'-oligoadenylate inhibit human immunodeficiency virus infection via inhibition of reverse transcriptase. Biochemistry, 30(8): 2027-2033.

34. Webb, C., Lehman, T., McCord, K., Avery, P., and Dow, S. (2008) Oxidative stress during acute FIV infection in cats. Vet. Immunol. Immunopathol., 122(1-2): 16-24.

35. Rodriguez-Valentin, M., Lopez, S., Rivera, M., RiosOlivares, E., Cubano, L. and Boukli, N.M. (2018) Naturally derived anti-HIV polysaccharide peptide (PSP) triggers a toll-like receptor 4-dependent antiviral immune response. $J$. Immunol. Res., 2018(15): Article ID 8741698.

36. Cardozo, F.T., Camelini, C.M., Mascarello, A., Rossi, M.J., Nunes, R.J., Barardi, C.R., de Mendonca, M.M. and Simoes, C.M. (2011) Antiherpetic activity of a sulfated polysaccharide from Agaricus brasiliensis mycelia. Antiviral Res., 92(1): 108-114.

37. Ou, C.B., Pan, Q., Chen, X., Hou, N. and He, C. (2012) Protocatechuic acid, a new active substance against the challenge of avian infectious bursal disease virus. Poult. Sci., 91(7): 1604-1609.

38. Zapora, E., Wolkowycki, M., Bakier, S. and Zjawiony, J.K. (2016) Phellinus igniarius: A pharmacologically active polypore mushroom. Nat. Prod. Commun., 11(7): 1043-1046. 